\title{
Urinary polyomavirus infections in neurodevelopmental disorders
}

\author{
Ivan Gentile $^{1,2}$, Laura Altieri ${ }^{3,4}$, Carla Lintas ${ }^{3,4}$, Roberto Sacco ${ }^{3,4}$, Paolo Curatolo ${ }^{5}$, Arianna Benvenuto ${ }^{5}$, \\ Filippo Muratori ${ }^{6}$, Elisa Santocchi ${ }^{6}$, Carmela Bravaccio ${ }^{7}$, Carlo Lenti $^{8}$, Raffaella Faggioli ${ }^{9}$, Roberto \\ Rigardetto $^{10}$, Marina Gandione ${ }^{10}$, Giuseppe Portella ${ }^{7}$, Emanuela Zappulo ${ }^{1}$, Guglielmo Borgia ${ }^{1,2}$, \\ Antonio M. Persico ${ }^{3,4,11}$ \\ ${ }^{1}$ Department of Clinical Medicine and Surgery, University of Naples "Federico II", Naples, Italy \\ ${ }^{2}$ Interdepartmental Center of Research in Basic and Clinical Immunological Science (CISI), University of Naples "Federico II", \\ Naples, Italy \\ ${ }^{3}$ Unit of Child and Adolescent Neuropsychiatry, Laboratory of Molecular Psychiatry and Neurogenetics, University "Campus Bio- \\ Medico", Rome, Italy \\ ${ }^{4}$ Department of Experimental Neurosciences, I.R.C.C.S. "Fondazione Santa Lucia", Rome, Italy \\ ${ }^{5}$ Department of Child Neuropsychiatry, University "Tor Vergata", Rome, Italy \\ ${ }^{6}$ Department of Child Neurology and Psychiatry, I.R.C.C.S. "Stella Maris", University of Pisa, Pisa, Italy \\ ${ }^{7}$ Department of Translational Medical Science, University "Federico II", Naples, Italy \\ ${ }^{8}$ Department of Child Neuropsychiatry, University of Milan, Italy \\ ${ }^{9}$ Fondazione Teda per l'Autismo ONLUS, Turin, Italy \\ ${ }^{10}$ Department of Child Neuropsychiatry, University of Turin, Turin, Italy \\ ${ }^{11}$ Mafalda Luce Center for Pervasive Developmental Disorders, Milan, Italy \\ Email: carmela.bravaccio@unina.it
}

Received 6 March 2013; revised 30 March 2013; accepted 8 April 2013

Copyright (C) 2013 Ivan Gentile et al. This is an open access article distributed under the Creative Commons Attribution License, which permits unrestricted use, distribution, and reproduction in any medium, provided the original work is properly cited.

\begin{abstract}
We have recently reported enhanced frequencies of polyomavirus infection in post-mortem brain tissue of autistic patients compared to controls. To further explore potential contributions to neurodevelopmental disorders by polyomaviruses, we have employed specie-specific TaqMan assays to assess the prevalence and titres of BKV, JCV and SV40 in the urines of 87 patients with autism spectrum disorder, 84 controls matched by sex and age with the autistic sample, 15 subjects with Down syndrome and 13 fragile $X$ individuals. Prevalence rates of urinary $B K V$ infection were significantly greater in Down syndrome and fragile $X$ patients compared to autistic and control individuals $(P<0.01)$. In a large majority of patients who showed the presence of urinary genomes, viral titres resulted significantly higher among Down syndrome patients $(P<0.01)$ compared to controls, autism spectrum disorder and fragile $X$ individuals, who did not significantly differ from each other. Our results are consistent with previous evidence supporting hampered immunological surveillance and/or immune deficits in fragile $X$ and especially in Down syndrome patients.
\end{abstract}

Keywords: Autism; BKV; Down Syndrome; Fragile X Syndrome; JCV; SV40

\section{INTRODUCTION}

Down syndrome (DS), fragile X syndrome (FXS) and autism spectrum disorder (ASD) represent three common developmental disorders encompassing abnormalities primarily affecting the central nervous system (CNS). DS is caused by a complete or partial trisomy of chromosome 21 [1]. The incidence of DS is directly proportional to maternal age and on average affects 1:750 live births [2]. The disease is associated with mental retardation, congenital cardiac defects, autoimmune disorders (celiac disease, hypothyroidism, type I diabetes mellitus), immunodeficiency with increased incidence of bacterial and viral infections, and early onset Alzheimer's disease [3-6]. Interestingly, both genome-wide and chromosome 21-targetted expression studies have unveiled the consistent over-expression of only approximately $25 \%-30 \%$ of trisomic genes, in addition to $3 \%-6 \%$ of loci distributed on each of the remaining chromosomes [7,8]. DS patients display prominent interindividual variability in clinical phenotype and disease severity, with approximately $8 \%$ showing severe autistic behaviours [9]. 
Fragile X syndrome (FXS) is caused by the expansion of a triplet repeat located in the 5' untranslated region (UTR) of the FMR1 gene (Xq27.3) [10]. When the normal 30-repeat allele becomes unstable and expands beyond 230 repeats, the FMR1 locus shows hypermethylated and transcription is silenced. Lack of the fragile $\mathrm{X}$ mental retardation protein (FMRP), an RNA-binding protein encoded by the FMR1 gene, is responsible for the disease phenotype [11]. The cardinal symptom of FXS is mental retardation and the phenotype is obviously more severe in males, who carry a single FMR1 allele [12]. Also in FXS a single and well-defined genetic abnormality translates into cognitive, behavioural and morphological signs and symptoms displaying significant interindividual variability [12]. In particular, approximately $40 \%$ of FXS patients are compatible with a diagnosis of autism, possibly reflecting specific neuroanatomical underpinnings [13].

ASD is characterized by deficits in social interaction and communication, as well as by stereotyped behaviours, with onset prior to 3 years of age [14]. Current psychiatric nosography distinguishes severe forms of the spectrum ("Autistic Disorder"), from conditions where speech is preserved ("Asperger Disorder") and from milder forms displaying some, but not all of the core symptoms ("Pervasive Developmental Disorder Not Otherwise Specified" or PDD-NOS) [14]. The incidence of ASD has dramatically risen during the last two decades from $2-5 / 10,000$ to approximately 2 - 6/1000 children $[15,16]$. Approximately $10 \%$ of ASD patients suffer from "syndromic" autism, i.e., secondary to a known genetic disorder, such as tuberous sclerosis, neurofibromatosis, FXS, and large chromosomal rearrangements, or to identified prenatal teratological agents, such as rubella and cytomegalovirus (CMV) infection, or exposure to drugs including thalidomide, misoprostol, and valproic acid [17-21]. The remaining $90 \%$ of patients are affected by non-syndromic or "idiopathic" autism. Altered neurodevelopment occurring during the first and second trimester of prenatal life is recognized as the underlying neuropathological cause of ASD in most patients [22]. Heritability estimates for autism are the highest among all neuropsychiatric disorders (see Discussion), but the genetic underpinnings of autism remain complex and largely elusive. Furthermore, several human studies have pointed toward possible viral contributions to the pathogenesis of ASD, compatible with high heritability and derangement of early prenatal neurodevelopment [23]. In particular, rubella and CMV represent the two infectious agents best-known to enhance autism risk following a congenital infection [23,24]. The largest longitudinal study involving several hundred children prenatally exposed to rubella virus estimates at $7.4 \%$ the rate of au- tism in this group (vs 2 - 6/1000 autism prevalence in the general population); risk appears especially high if the infection occurs during the first 8 weeks post-conception [17]. Evidence linking prenatal CMV infection to autism is more circumstantial: several case reports have been published, but risk estimates are essentially based on a small cohort of 7 prenatally CMV-infected children, who displayed autistic features in 2 cases $(2 / 7=28.6 \%)$ [21]. It remains to be determined to what extent autism ensues from direct viral damage, from the strong immune response driven by herpes viruses, such as CMV, or from the nature and location of cerebral malformations which are particularly frequent in congenital CMV infection. Autistic children prenatally infected with rubella or CMV typically display "low-functioning" autism, accompanied by severe mental retardation, seizures, and physical anomalies, such as ophthalmologic malformations, deafness, cardiac malformations. Brain imaging findings are highly variable, ranging from normal to cortical malformations (polymicrogyria, pachygyria, heterotopias) indicative of migration defects, to abnormal intensity of the periventricular white matter suggestive of abnormal myelination in the absence of any cortical malformation. These clinical and brain imaging features are not typical of most "idiopathic" autistic children, as prenatal rubella and CMV do not represent frequent causes of autism. Nonetheless this pathogenetic paradigm demonstrates that prenatal viral infections can indeed cause autism and that other viral species could be involved, provided their mechanism is reconciled with high heritability and with an early prenatal onset for deranged neurodevelopment later leading to abnormal behaviour.

We have recently reported enhanced frequencies of polyomavirus (BKV, JCV and SV40) infection in postmortem neocortical tissue of ASD patients compared to controls [25]. Multiple lines of evidence support vertical transmission of polyomaviruses as a potential cause of autism in a sizable subgroup of patients (see Discussion). In the present study, we assess the prevalence and titres of BKV, JCV and SV40 in the urines of 64 ASD, 15 DS, and 13 FXS patients, as well as 64 controls tightly matched by sex and age with the ASD sample.

\section{MATERIALS AND METHODS}

\subsection{Urine Samples}

Urines from 87 ASD children, 15 individuals with DS, and 13 FXS patients were collected. Tight sex- and agematching ( $\pm 2 \mathrm{yr}$ ) to the ASD sample was applied to recruit 84 typically developing controls among the offspring of staff members devoid at the time of any overt sign or symptom of illness. The demographic characteristics of the four experimental groups are summarized in 
Table 1. Urine samples were stored at $-80^{\circ} \mathrm{C}$ until analysis. Viral DNA was extracted from $140 \mu$ l of urine, using a commercially available kit (QIAamp Viral RNA Minikit, Qiagen, Inc.), according to the manufacturer's instructions.

\subsection{Real Time PCR}

Urinary titres of viral DNA were quantified by real time PCR using appropriate TaqMan assays (Applied Biosystems, Foster City, CA). Briefly, a standard curve was prepared for each assay using a serial 10-fold dilution of plasmids containing the appropriate viral genome (range $0-10^{8}$ copies). Each sample was assayed in triplicate. BKV, JCV or SV40 viral loads are expressed as copies/ $\mu \mathrm{l}$ of urine. A BKV or JCV gene sequence from the VP1 region and an SV40 gene sequence from the early coding region were amplified using the primers and probes listed in Table 2. TaqMan probes were labelled with FAM and TAMRA at 5' and 3', respectively. PCR cycling conditions for all viral species were $95^{\circ} \mathrm{C}$ for 10 min, followed by 40 cycles at $95^{\circ} \mathrm{C}$ for $15 \mathrm{sec}$ and $60^{\circ} \mathrm{C}$ for $1 \mathrm{~min}$. PCR was performed in a total volume of $25 \mu \mathrm{l}$, including MasterMix Genotyping 2x (Applied Biosystems, Foster City, CA), $400 \mathrm{nM}$ of each primer (Invitrogen, Carlsbad, CA) and $200 \mathrm{nM}$ probe (Applied Biosystems, Foster City, CA). The sensitivity of TaqMan assays for BKV and JCV was at 100 copies/ $\mu 1$, whereas SV40 was at 10 - 100 copies/ $\mu$; all assays were completely specie-specific, except for the BKV assay which amplifies JCV at high titres $\left(10^{5}-10^{8}\right.$ copies $\left./ \mu \mathrm{l}\right)$ not recorded in any individual assessed here.

\subsection{Statistical Analysis}

Prevalence rates of polyomavirus infection in urines were compared using the $\mathrm{X}^{2}$ test and Fisher's exact test, where appropriate. Kolmogorov-Smirnov test was applied to check for Gaussian distribution of quantitative variables. In case of Gaussian distribution mean and SD were used to present data and ANOVA test for comparing variables. In case of non-Gaussian distribution, median and interquartile range (IQR) were used to present data and Kruskal-Wallis test was employed to compare them. Two-tail $\mathrm{P}$ values are reported throughout the manuscript.

\section{RESULTS}

The prevalence of urinary Polyomavirus infection in ASD, DS, FXS patients and controls is shown in Table 3. DS and FXS individuals display greater-than-double prevalence rates of urinary $\mathrm{BKV}$ infection compared to ASD and controls, as BKV is present in 8/15 (53.5\%) DS and $8 / 13(61.5 \%)$ FXS individuals vs $21 / 84$ (25\%) controls and 16/87 (18.4\%) ASD patients $\left(\mathrm{X}^{2}=16.718,3 \mathrm{df}\right.$, $\mathrm{P}=0.001)$.

Urinary BKV titres, measured by specie-specific TaqMan assay in 15 ASD, 8 FXS, 8 DS, and 17 controls positive for this virus are significantly different among the four diagnostic groups $\left(\mathrm{K}-\mathrm{W} \mathrm{X} \mathrm{X}^{2}=11.60,3 \mathrm{df}, \mathrm{P}=\right.$ 0.009). DS individuals show 2 - 3 times higher urinary BKV titres compared to the other three diagnostic groups, which do not differ from each other (DS vs controls, $\mathrm{U}=$ $14, \mathrm{P}=0.002$; DS vs ASD: $\mathrm{U}=18, \mathrm{P}=0.007$; DS vs $\mathrm{FXS}, \mathrm{U}=13, \mathrm{P}=0.046$ ).

Urinary titres of BKV did not differ significantly between ASD and control group. Prevalence rates of urinary JCV and SV40 infection did not differ among ASD, DS, FXS patients and controls (Table 3). These two species were found in 14 out of a total of 199 individuals recruited for this study: the small number of positive samples hindered meaningful quantitative analyses of urinary viral titres for JCV and SV40.

\section{DISCUSSION}

The present study reports enhanced rates of urinary BKV infection in DS and FXS patients compared to controls and autistic individuals, as well as significantly elevated urinary BKV titres in DS patients. Our experimental approach appears both reliable and valid. The TaqMan assays used to quantify urinary BKV, JCV, and SV40 titres were previously described [26-28], and have yielded in our hands sensitivities and specificities superimposable to those reported in the original publications. Each urine sample was analysed in triplicate and the four diagnostic subgroups were always assayed in parallel. The higher prevalence of urinary infection by BKV compared to JCV was initially unexpected, as the vast majority of studies involving immunocompetent individuals indeed show the opposite trend [29]. However, these studies typically

Table 1. Demographic characteristics of the sample.

\begin{tabular}{cccccc}
\hline & $\mathrm{N}$ & Males & Females & Median Age (years) & IQR (years) \\
\hline Controls & 84 & $66(78.6 \%)$ & $18(21.4 \%)$ & 7.0 & $5.0-10.0$ \\
ASD & 87 & $70(80.5 \%)$ & $17(19.5 \%)$ & 7.0 & $4.8-10.0$ \\
DS & 15 & $12(80.0 \%)$ & $3(20.0 \%)$ & 11.0 & $7.8-18.0$ \\
FXS & 13 & $11(84.6 \%)$ & $2(15.4 \%)$ & 15.0 & $9.0-20.0$ \\
\hline
\end{tabular}


Table 2. Primers and probes used in TaqMan assays to quantify viral titres.

\begin{tabular}{|c|c|c|c|}
\hline Virus & Primer/Probe Name & Primer/Probe Sequence (5' - 3') & Reference \\
\hline \multirow{3}{*}{ BKV } & VP1 Din For & TGCTGATATTTGTGGCCTGTTTACTA & \multirow{3}{*}{ [26] } \\
\hline & VP1 Din Rev & CTCAGGCGGATCTTAAAATATCTTG & \\
\hline & VP1 Din Probe & 6-FAM-AGCTCTGGAACACAACAGTGGAGAGGCC-TAMRA & \\
\hline \multirow{3}{*}{$\mathrm{JCV}$} & JC VP1 F bis & CTCAATGGATGTTGCCTTTACTT & \multirow{3}{*}{ mod. from $[27]$} \\
\hline & $\mathrm{JC}$ VP1 R bis & CGGGGTCCTTCCTTTCTCC & \\
\hline & JC VP1 Probe & 6-FAM-AGGGTTGTACGGGACTGTAACACCTGCTC-TAMRA & \\
\hline \multirow{3}{*}{ SV40 } & SE2 early For & GTGGAATGCCTTTAATGAGGAAA & \multirow{3}{*}{ [28] } \\
\hline & SE2 early Rev & TTGAGAGTCAGCAGTAGCCTCATC & \\
\hline & SE2 early Probe & 6-FAM-CCTGTTTTGCTCAGAAGAAATGCCATCTAGTG-TAMRA & \\
\hline
\end{tabular}

Table 3. Prevalence of urinary BKV, JCV and SV40 infection.

\begin{tabular}{cccccc}
\hline & Controls $(\mathrm{N}=84)$ & ASD $(\mathrm{N}=87)$ & Down $(\mathrm{N}=15)$ & FXS (N=13) & Statistics \\
\hline BKV+ & $21(25.0 \%)$ & $16(18.4 \%)$ & $8(53.3 \%)$ & $8(61.5 \%)$ & $\mathrm{X}^{2}=16.718,3 \mathrm{df}, \mathrm{P}=0.001$ \\
$\mathrm{BKV}-$ & $63(75.0 \%)$ & $71(81.6 \%)$ & $7(46.7 \%)$ & $5(38.5 \%)$ & \\
$\mathrm{JCV}+$ & $3(3.6 \%)$ & $2(2.3 \%)$ & $0(0 \%)$ & $2(15.4 \%)$ & $\mathrm{X}^{2}=6.323,3 \mathrm{df}, \mathrm{P}=0.097$, n.s. \\
$\mathrm{JCV}-$ & $81(96.4 \%)$ & $85(97.7 \%)$ & $15(100 \%)$ & $11(84.6 \%)$ & \\
$\mathrm{SV} 40+$ & $* 3(4.7 \%)$ & $* 1(1.6 \%)$ & $2(13.3 \%)$ & $1(7.7 \%)$ & $\mathrm{X}^{2}=4.33,3 \mathrm{df}, \mathrm{P}=0.23$, n.s. \\
$\mathrm{SV} 40-$ & $* 61(95.3 \%)$ & $* 63(98.4 \%)$ & $13(86.7 \%)$ & $12(92.3 \%)$ & \\
\hline
\end{tabular}

Note: $+=$ present, $-=$ absent, ${ }^{*} \mathrm{~N}=64$.

enrolled adult or elderly subjects. Interestingly, a large study performed by Zhong et al. [30] on 450 immunocompetent individuals stratified by age $(\mathrm{N}=50$ per decade) reported $0-9 \mathrm{yr}$ as the only age group displaying greater incidence of urinary BKV infection compared to $\operatorname{JCV}(12 / 50=24 \%$ vs $5 / 50=10 \%$ for BKV and JCV, respectively). Infection rates are equal for BKV and JCV in the 10 - 19 yr age group (16\% positives for each virus) and were consistently higher for JCV over BKV in all age groups starting at $20-29$ years and beyond [30]. Importantly, the rates of urinary $\mathrm{BKV}$ infection reported by Zhong et al. [30] in their pediatric immunocompetent individuals are superimposable to the prevalence we detect in our controls and autistic children (Table 3). Also rates of urinary SV40 infection close to $5 \%$ have been previously described in healthy pediatric samples [31]. Furthermore, in addition to TaqMan assays, we also applied the same nested-PCR protocol previously employed in our study of post-mortem brains [25]. Although the greater sensitivity of nested PCR (positive at 1 copy/ $\mu$ l) yields high prevalence rates (data not shown) not comparable with previously published results, this second approach allowed us to definitively confirm the speciespecificity of our assessment by DNA sequencing and/or restriction digest. These pieces of evidence collectively raise confidence in the reliability of our results, showing that FXS and especially DS individuals may be particularly liable to develop urinary BKV infection, as compared to controls and ASD subjects.

The present report is in line with previous data linking DS to increased incidence of bacterial and viral infections [5,32], as well as to immunodeficiency and decreased response to vaccination [33-37]. Several factors contribute since early childhood to diminish humoral and especially cell-mediated immunological surveillance in DS $[4,38,39]$, increasing the incidence of primary and recurrent infections, while facilitating the reactivation of latent infections. In addition, DS has been classified as a progeroid, with premature ageing further fostering immunological alterations, autoimmune diseases and neoplasms at a younger age compared to the general population $[40,41]$. Although the age distribution of DS individuals in our sample should minimize the role of premature ageing in decreased immunological surveillance and enhanced urinary polyomavirus infection rates, moderate contributions cannot be excluded in our older DS subjects. Also FXS appears associated with increased susceptibility to infections [42], perhaps due to abnormal 
cytokine and chemokine levels [43], but much fewer data are available in the literature for FXS compared to DS in this regard.

ASD has been identified by family and twin studies as the most "heritable" neuropsychiatric disorder, with concordance rates of $82 \%-92 \%$ in monozygotic (MZ) twins vs $1 \%-10 \%$ in dizygotic (DZ) twins; sibling recurrence risk is 3\%- $6 \%$ for strict autism and approximately $15 \%$ for broad ASD, much higher than prevalence estimates in the general population [20,44-46]. Yet, two decades of genetic investigation have unveiled relatively few cases which can be solely explained on the basis of de novo mutations or cytogenetic abnormalities [47]. We have thus hypothesized that vertical viral transmission from parents to offspring mediated by parental gametes may play a role in autism $[25,48]$. In our recent post-mortem study, the presence of polyomavirus genomes in neocortical tissue was significantly associated with an ASD diagnosis [25]. Converging lines of evidence, obtained using these same brain tissues either directly or indirectly, support an inappropriate and persistent activation of the innate immune system in ASD, compatible with an early unresolved viral infection in the CNS of many autistic individuals [49-51]. Furthermore, several ASD children display immunological abnormalities, which could point toward abnormal handling of viral agents by the immune system [52,53]. Strikingly, as many as $48 \%$ of ASD children display MRI abnormalities strongly resembling CNS viral infections, especially around the temporal lobes [54]. Also the HGF/MET pathway has been demonstrated to undergo strong activation during SV40 replication and the gene encoding MET is significantly associated with autism $[55,56]$.

The presence of genome in urine of immunocompetent subjects is only an indicator of current infection or viral reactivation, not a reliable marker of life-time exposure. In this regard, the higher rate of BKV genome detection in patients with DS, which is associated with marked immune deficits, is consistent with a reactivation from such viruses. The potential contribution of infection/reactivation by polyomavirus in shaping the clinical phenotype of these neurogenetic syndromes remains unknown.

On the other hand, ASD patients do not differ here from controls in prevalence rate of urinary polyomavirus infection and in viral titres. This negative finding is not necessarily incompatible with prenatal or early postnatal roles of polyomaviruses in ASD, since congenital infections by viral agents, such as CMV and HSV1, does not largely result in persistent or recurrent shedding later in life, and the duration of viral excretion is not correlated with long term outcome $[57,58]$. We are thus testing our hypothesis by directly assessing the prevalence of gametic infection in parents of ASD children. Also serological assays able to detect virus-specific serum anti- bodies should provide an estimate of lifetime exposure rates in ASD and control subjects. These two experimental approaches should jointly provide a conclusive test of the possible role of polyomavirus infections which, occurring in a very early embryological period, could be involved in the pathogenesis of these disorders.

\section{ACKNOWLEDGEMENTS}

We gratefully acknowledge the patients and families who participated in this study, Mauro Tognon and Fernanda Martini for kindly providing $\mathrm{BKV}, \mathrm{JCV}$, and SV40 genomes cloned into plasmid vectors, and Armando Felsani for his kind collaboration. This work was supported by the Italian Ministry for University, Scientific Research and Technology (Programmi di Ricerca di Interesse Nazionale, prot. n. 2006058195 and n. 2008BACT54), the Italian Ministry of Health (RFPS-2007-5-640174), the Autism Research Institute (San Diego, CA) and the Autism Speaks Foundation (Princeton, NJ).

\section{REFERENCES}

[1] Lejeune, J., Gautier, M. and Turpin, R. (1959) Study of somatic chromosomes from 9 mongoloid children. Les Comptes Rendus Hebdomadaires des Séances de L'Académie des Sciences, 248, 1721-1722.

[2] Girirajan, S. (2009) Parental-age effects in Down syndrome. Journal of Genetics, 88, 1-7. doi:10.1007/s12041-009-0001-6

[3] Yamato, F., Takaya, J., Yasuhara, A., Teraguchi, M., Ikemoto, Y. and Kaneko, K. (2009) Elevated intracellular calcium in neutrophils in patients with Down syndrome. Pediatrics International, 51, 474-477. doi:10.1111/j.1442-200X.2008.02761.x

[4] de Hingh, Y.C., van der Vossen, P.W., Gemen, E.F., Mulder, A.B., Hop, W.C., Brus, F. and de Vries, E. (2005) Intrinsic abnormalities of lymphocyte counts in children with down syndrome. Journal of Pediatrics, 147, 744747. doi:10.1016/j.jpeds.2005.07.022

[5] Ribeiro, L.M., Jacob, C.M., Pastorino, A.C., Kim, C.A., Fomin, A.B. and Castro, A.P. (2003) Evaluation of factors associated with recurrent and/or severe infections in patients with Down's syndrome. Journal of Pediatrics, 79, 141-148. doi:10.1590/S0021-75572003000200009

[6] Elsayed, S.M. and Elsayed, G.M. (2009) Phenotype of apoptotic lymphocytes in children with Down syndrome. Immunity \& Ageing, 6, 2. doi:10.1186/1742-4933-6-2

[7] Ait Yahya-Graison, E., Aubert, J., Dauphinot, L., Rivals, I., Prieur, M., Golfier, G., Rossier, J., Personnaz, L., Creau, N., Blehaut, H., Robin, S., Delabar, J.M. and Potier, M.C. (2007) Classification of human chromosome 21 gene-expression variations in Down syndrome: Impact on disease phenotypes. American Journal of Human Genetics, 81, 475-491. doi:10.1086/520000

[8] Lockstone, H.E., Harris, L.W., Swatton, J.E., Wayland, M.T., Holland, A.J. and Bahn, S. (2007) Gene expression profiling in the adult Down syndrome brain. Genomics, 90, 647-660. doi:10.1016/j.ygeno.2007.08.005 
[9] Zafeiriou, D.I., Ververi, A. and Vargiami, E. (2007) Childhood autism and associated comorbidities. Brain \& Development, 29, 257-272. doi:10.1016/j.braindev.2006.09.003

[10] Pieretti, M., Zhang, F.P., Fu, Y.H., Warren, S.T., Oostra, B.A., Caskey, C.T. and Nelson, D.L. (1991) Absence of expression of the FMR-1 gene in fragile $\mathrm{X}$ syndrome. Cell, 66, 817-822. doi:10.1016/0092-8674(91)90125-I

[11] Weiler, I.J., Irwin, S.A., Klintsova, A.Y., Spencer, C.M., Brazelton, A.D., Miyashiro, K., Comery, T.A., Patel, B., Eberwine, J. and Greenough, W.T. (1997) Fragile X mental retardation protein is translated near synapses in response to neurotransmitter activation. Proceedings of the National Academy of Sciences of the United States of America, 94, 5395-5400. doi:10.1073/pnas.94.10.5395

[12] Turner, G., Daniel, A. and Frost, M. (1980) X-linked mental retardation, macro-orchidism, and the Xq27 fragile site. Journal of Pediatrics, 96, 837-841. doi:10.1016/S0022-3476(80)80552-X

[13] Belmonte, M.K. and Bourgeron, T. (2006) Fragile X syndrome and autism at the intersection of genetic and neural networks. Nature Neuroscience, 9, 1221-1225. doi:10.1038/nn1765

[14] American Psychiatric Association (1994) Diagnostic and statistical manual of mental disorders. 4th Editon, American Psychiatric Press, Washington DC.

[15] Fombonne, E. (2005) Epidemiology of autistic disorder and other pervasive developmental disorders. Journal of Clinical Psychiatry, 66, 3-8.

[16] Rutter, M. (2005) Incidence of autism spectrum disorders: Changes over time and their meaning. Acta Paediatrica, 94, 2-15. doi:10.1080/08035250410023124

[17] Chess, S., Fernandez, P. and Korn, S. (1978) Behavioral consequences of congenital rubella. Journal of Pediatrics, 93, 699-703. doi:10.1016/S0022-3476(78)80921-4

[18] Christianson, A.L., Chesler, N. and Kromberg, J.G. (1994) Fetal valproate syndrome: Clinical and neuro-developmental features in two sibling pairs. Developmental Medicine \& Child Neurology, 36, 361-369. doi:10.1111/j.1469-8749.1994.tb11858.x

[19] Miller, M.T., Stromland, K., Ventura, L., Johansson, M., Bandim, J.M. and Gillberg, C. (2005) Autism associated with conditions characterized by developmental errors in early embryogenesis: A mini review. International Journal of Developmental Neuroscience, 23, 201-219. doi:10.1016/j.ijdevneu.2004.06.007

[20] Persico, A.M. and Bourgeron, T. (2006) Searching for ways out of the autism maze: Genetic, epigenetic and environmental clues. Trends in Neurosciences, 29, 349-358. doi:10.1016/j.tins.2006.05.010

[21] Yamashita, Y., Fujimoto, C., Nakajima, E., Isagai, T. and Matsuishi, T. (2003) Possible association between congenital cytomegalovirus infection and autistic disorder. Journal of Autism and Developmental Disorders, 33, 455-459. doi:10.1023/A:1025023131029

[22] DiCicco-Bloom, E., Lord, C., Zwaigenbaum, L., Courchesne, E., Dager, S.R., Schmitz, C., Schultz, R.T., Crawley, J. and Young, L.J. (2006) The developmental neuro- biology of autism spectrum disorder. Journal of Neuroscience, 26, 6897-6906.

doi:10.1523/JNEUROSCI.1712-06.2006

[23] Libbey, J.E., Sweeten, T.L., McMahon, W.M. and Fujinami, R.S. (2005) Autistic disorder and viral infections. Journal of Neurovirology, 11, 1-10. doi:10.1080/13550280590900553

[24] van den Pol, A.N. (2006) Viral infections in the developing and mature brain. Trends in Neuroscience, 29, 398406. doi:10.1080/13550280590900553

[25] Lintas, C., Altieri, L., Lombardi, F., Sacco, R. and Persico, A.M. (2010) Association of autism with polyomavirus infection in postmortem brains. Journal of Neurovirology, 16, 141-149. doi:10.3109/13550281003685839

[26] Ding, R., Medeiros, M., Dadhania, D., Muthukumar, T., Kracker, D., Kong, J.M., Epstein, S.R., Sharma, V.K., Seshan, S.V., Li, B. and Suthanthiran, M. (2002) Noninvasive diagnosis of $\mathrm{BK}$ virus nephritis by measurement of messenger RNA for BK virus VP1 in urine. Transplantation, 74, 987-994.

[27] Randhawa, P., Shapiro, R. and Vats, A. (2005) Quantitation of DNA of polyomaviruses BK and JC in human kidneys. Journal of Infectious Diseases, 192, 504-509. doi: $10.1086 / 431522$

[28] Pal, A., Sirota, L., Maudru, T., Peden, K. and Lewis Jr., A.M. (2006) Real-time, quantitative PCR assays for the detection of virus-specific DNA in samples with mixed populations of polyomaviruses. Journal of Virological Methods, 135, 32-42. doi:10.1016/j.jviromet.2006.01.018

[29] Knowles, W. (2006) Discovery and epidemiology of the human polyomaviruses BK Virus (BKV) and JC Virus (JCV) in Polyomaviruses and Human Disease. In: Ahsan, N., Ed., Advances in Experimental Medicine and Biology, Landes Bioscience, Georgetown, 117-147. doi:10.1007/0-387-32957-9_2

[30] Zhong, S., Zheng, H.Y., Suzuki, M., Chen, Q., Ikegaya, H., Aoki, N., Usuku, S., Kobayashi, N., Nukuzuma, S., Yasuda, Y., Kuniyoshi, N., Yogo, Y. and Kitamura, T. (2007) Age-related urinary excretion of BK polyomavirus by nonimmunocompromised individuals. Journal of Clinical Microbiology, 45, 193-198. doi:10.1128/JCM.01645-06

[31] Vanchiere, J.A., White, Z.S. and Butel, J.S. (2005) Detection of BK virus and simian virus 40 in the urine of healthy children. Journal of Medical Virology, 75, 447 454. doi:10.1002/jmv. 20287

[32] Garrison, M.M., Jeffries, H. and Christakis, D.A. (2005) Risk of death for children with down syndrome and sepsis. Journal of Pediatrics, 147, 748-752. doi:10.1016/j.jpeds.2005.06.032

[33] Avanzini, M.A., Monafo, V., De Amici, M., Maccario, R., Burgio, G.R., Plebani, A., Ugazio, A.G. and Hanson, L.A. (1990) Humoral immunodeficiencies in Down syndrome: Serum IgG subclass and antibody response to hepatitis B vaccine. American Journal of Medical Genetics, 7, 231233.

[34] Costa-Carvalho, B.T., Martinez, R.M., Dias, A.T., Kubo, C.A., Barros-Nunes, P., Leiva, L., Sole, D., CarneiroSampaio, M.M., Naspitz, C.K. and Sorensen, R.U. (2006) 
Antibody response to pneumococcal capsular polysaccharide vaccine in Down syndrome patients. Brazilian Journal of Medical and Biological Research, 39, 15871592. doi:10.1590/S0100-879X2006005000047

[35] Epstein, L.B. and Philip, R. (1987) Abnormalities of the immune response to influenza antigen in Down syndrome (trisomy 21). Progress in Clinical Biological Research, 246, 163-182.

[36] Ferreira, C.T., Leite, J.C., Taniguchi, A., Vieira, S.M., Pereira-Lima, J. and da Silveira, T.R. (2004) Immunogenicity and safety of an inactivated hepatitis A vaccine in children with Down syndrome. Journal of Pediatric Gastroenterology and Nutrition, 39, 337-340. doi:10.1097/00005176-200410000-00007

[37] Philip, R., Berger, A.C., McManus, N.H., Warner, N.H., Peacock, M.A. and Epstein, L.B. (1986) Abnormalities of the in vitro cellular and humoral responses to tetanus and influenza antigens with concomitant numerical alterations in lymphocyte subsets in Down syndrome (trisomy 21). Journal of Immunology, 136, 1661-1667.

[38] Burgio, G.R., Lanzavecchia, A., Maccario, R., Vitiello, A., Plebani, A. and Ugazio, A.G. (1978) Immunodeficiency in Down's syndrome: T-lymphocyte subset imbalance in trisomic children. Clinical \& Experimental Immunology, 33, 298-301.

[39] Verstegen, R.H., Kusters, M.A., Gemen, E.F., et al. (2010) Down syndrome B-lymphocyte subpopulations, intrinsic defect or decreased T-lymphocyte help. Pediatric Research, 67, 563-569. doi:10.1203/PDR.0b013e3181d4ecc1

[40] Cossarizza, A., Monti, D., Montagnani, G., Ortolani, C., Masi, M., Zannotti, M. and Franceschi, C. (1990) Precocious aging of the immune system in Down syndrome: Alteration of B lymphocytes, T-lymphocyte subsets, and cells with natural killer markers. American Journal of Medical Genetics, 7, 213-218.

[41] Lockitch, G., Singh, V.K., Puterman, M.L., Godolphin, W.J., Sheps, S., Tingle, A.J., Wong, F. and Quigley, G. (1987) Age-related changes in humoral and cell-mediated immunity in Down syndrome children living at home. Pediatric Research, 22, 536-540. doi:10.1203/00006450-198711000-00013

[42] Hagerman, R.J. and Hagerman, P.J. (2002) Fragile X syndrome: Diagnosis, treatment and research. 3rd Edition, T.J.H.U. Press, Baltimore.

[43] Ashwood, P., Nguyen, D.V., Hessl, D., Hagerman, R.J. and Tassone, F. (2010) Plasma cytokine profiles in fragile X subjects: Is there a role for cytokines in the pathogenesis? Brain, Behavior, and Immunity, 24, 898-902. doi:10.1016/j.bbi.2010.01.008

[44] Abrahams, B.S. and Geschwind, D.H. (2008) Advances in autism genetics: On the threshold of a new neurobiology. Nature Reviews Genetics, 9, 341-355. doi: $10.1038 / \mathrm{nrg} 2346$

[45] Freitag, C.M. (2007) The genetics of autistic disorders and its clinical relevance: A review of the literature. Molecular Psychiatry, 12, 2-22. doi:10.1038/sj.mp.4001896

[46] Weiss, L.A. (2009) Autism genetics: Emerging data from genome-wide copy-number and single nucleotide polymorphism scans. Expert Review of Molecular Diagnostics, 9, 795-803. doi:10.1586/erm.09.59

[47] Lintas, C. and Persico, A.M. (2009) Autistic phenotypes and genetic testing: State-of-the-art for the clinical geneticist. Journal of Medical Genetics, 46, 1-8. doi:10.1136/jmg.2008.060871

[48] Persico, A.M. (2010) Polyomaviruses and autism: More than simple association? Journal of Neurovirology, 16, 332-333. doi:10.3109/13550284.2010.504765

[49] Garbett, K., Ebert, P.J., Mitchell, A., Lintas, C., Manzi, B., Mirnics, K. and Persico, A.M. (2008) Immune transcriptome alterations in the temporal cortex of subjects with autism. Neurobiology of Disease, 30, 303-311. doi:10.1016/j.nbd.2008.01.012

[50] Lintas, C., Sacco, R., Garbett, K., Mirnics, K., Militerni, R., Bravaccio, C., Curatolo, P., Manzi, B., Schneider, C., Melmed, R., Elia, M., Pascucci, T., Puglisi-Allegra, S., Reichelt, K.L. and Persico, A.M. (2009) Involvement of the PRKCB1 gene in autistic disorder: Significant genetic association and reduced neocortical gene expression. Molecular Psychiatry, 14, 705-718. doi:10.1038/mp.2008.21

[51] Palmieri, L., Papaleo, V., Porcelli, V., Scarcia, P., Gaita, L., Sacco, R., Hager, J., Rousseau, F., Curatolo, P., Manzi, B., Militerni, R., Bravaccio, C., Trillo, S., Schneider, C., Melmed, R., Elia, M., Lenti, C., Saccani, M., Pascucci, T., Puglisi-Allegra, S., Reichelt, K.L. and Persico, A.M. (2010) Altered calcium homeostasis in autism-spectrum disorders: Evidence from biochemical and genetic studies of the mitochondrial aspartate/glutamate carrier AGC1. Molecular Psychiatry, 15, 38-52. doi:10.1038/mp.2008.63

[52] Vargas, D.L., Nascimbene, C., Krishnan, C., Zimmerman, A.W. and Pardo, C.A. (2005) Neuroglial activation and neuroinflammation in the brain of patients with autism. Annals of Neurology, 57, 67-81. doi:10.1002/ana.20315

[53] Ashwood, P., Wills, S. and Van de Water, J. (2006) The immune response in autism: A new frontier for autism research. Journal of Leukocyte Biology, 80, 1-15. doi:10.1189/jlb.1205707

[54] Boddaert, N., Zilbovicius, M., Philipe, A., Robel, L., Bourgeois, M., Barthelemy, C., Seidenwurm, D., Meresse, I., Laurier, L., Desguerre, I., Bahi-Buisson, N., Brunelle, F., Munnich, A., Samson, Y., Mouren, M.C. and Chabane, N. (2009) MRI findings in 77 children with non-syndromic autistic disorder. PLoS One, 4, 10. doi:10.1371/journal.pone.0004415

[55] Cacciotti, P., Libener, R., Betta, P., Martini, F., Porta, C., Procopio, A., Strizzi, L., Penengo, L., Tognon, M., Mutti, L. and Gaudino, G. (2001) SV40 replication in human mesothelial cells induces HGF/Met receptor activation: A model for viral-related carcinogenesis of human malignant mesothelioma. Proceedings of the National Academy of Sciences of the United States of America, 98, 1203212037. doi:10.1073/pnas.211026798

[56] Campbell, D.B., Sutcliffe, J.S., Ebert, P.J., Militerni, R., Bravaccio, C., Trillo, S., Elia, M., Schneider, C., Melmed, R., Sacco, R., Persico, A.M. and Levitt, P. (2006) A 
genetic variant that disrupts MET transcription is associated with autism. Proceedings of the National Academy of Sciences of the United States of America, 103, 1683416839. doi:10.1073/pnas.0605296103

[57] Pass, R.F., Stagno, S., Britt, W.J. and Alford, C.A. (1983) Specific cell-mediated immunity and the natural history of congenital infection with cytomegalovirus. Journal of Infectious Diseases, 148, 953-961. doi:10.1093/infdis/148.6.953
[58] Noyola, D.E., Demmler, G.J., Williamson, W.D., Griesser, C., Sellers, S., Llorente, A., Littman, T., Williams, S., Jarrett, L., Yow, M.D. and Congenital CMV Longitudinal Study Group (2000) Cytomegalovirus urinary excretion and long term outcome in children with congenital cytomegalovirus infection. Pediatric Infectious Disease Journal, 19, 505-510.

doi:10.1097/00006454-200006000-00003 